\title{
Pembuatan Teh Bawang Dayak dan Manfaatnya Bagi Kader Pusat Kesehatan Masyarakat Harapan Baru Samarinda Seberang
}

\section{Production of Bawang Dayak Tea and Its Benefits for Cadres of Harapan Baru Community Health Center Samarinda Seberang}

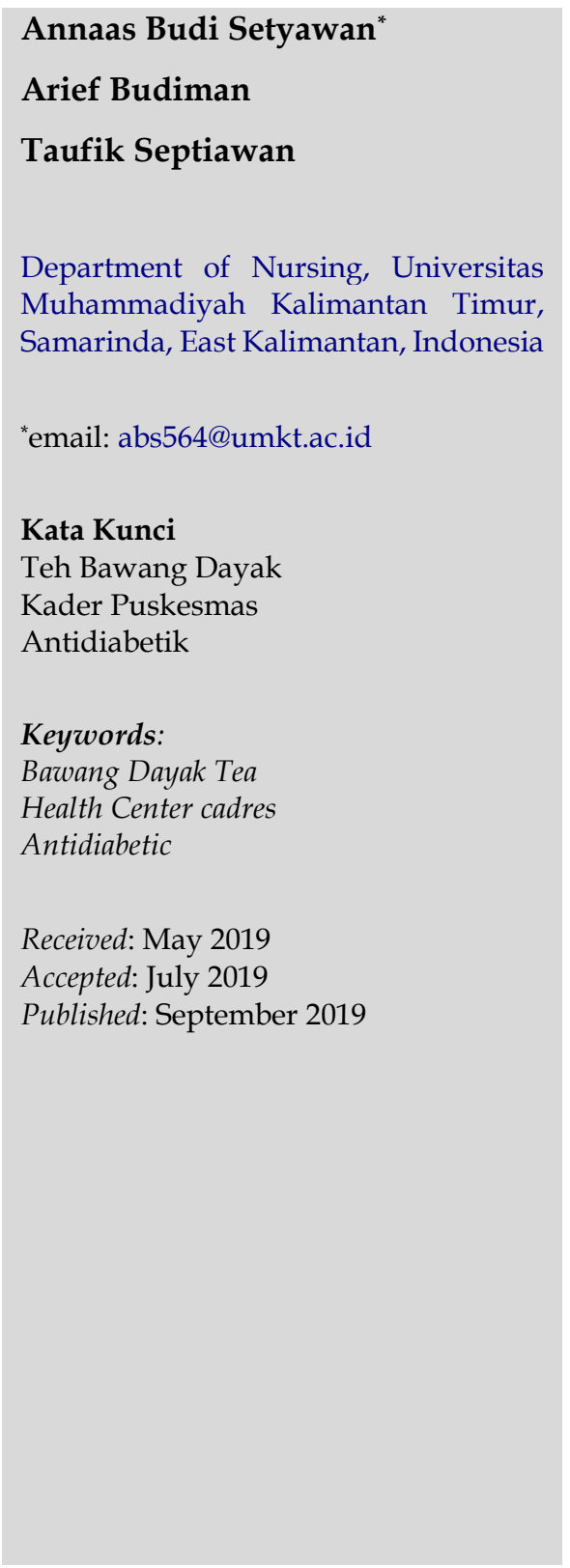

\begin{abstract}
Abstrak
Kegiatan pengabdian masyarakat ini di hadiri oleh kader Pusast Kesehatan Masyarakat (Puskesmas) Harapan Baru Samarinda Seberang yang mengikuti acara pembuatan teh bawang dayak dari awal hingga selesai acara, disamping itu didalam kegiatan ini juga diberikan pendidikan kesehatan kepada para kader mengenai penyakit tekanan darah tinggi dan juga kencing manis. Kegiatan ini memiliki tujuan utama mengajak kader Puskesmas untuk memanfaatkan hasil tanaman alam yaitu bawang dayak yang dapat diolah menjadi teh dan dapat diambil manfaatnya untuk kesehatan serta memiliki nilai ekonomi. Dalam memanfaatkan tanaman bawang dayak ini perlu pengolahan yang baik agar kandungannya tidak berkurang. Langkah pertama yaitu memotong akar dan daunnya, selanjutnya mencucinya pada air yang mengalir, kemudian di iris secara menyerong lalu dikeringkan, sebelumnya akhirnya disimpan dalam wadah yang kedap udara. Pemanfaatan bawang dayak yang kemudian di olah menjadi teh hal ini berarti mendorong pemanfaatan tanaman khas Kalimantan menjadi sumber alternatif bagi kesehatan serta kemampuan untuk mengolah tanaman ini menjadi sebuah produk berarti meningkatkan peluang ekonomi untuk berkontibusi dalam penyelesaian masalah sosial.
\end{abstract}

\begin{abstract}
The community service activity was attended by cadres of Harapan Baru Community Health Center (Puskesmas) Samarinda Seberang who participated at the bawang dayak tea making program from the beginning to the end of the event, besides that in this activity also provided health education to the cadres about high blood pressure and even diabetes. This activity has the primary purpose of inviting Puskesmas cadres to utilize natural plant products bawang dayak, which can be processed into tea and can be taken for health benefits and have economic value. In using this bawang dayak plant, it needs proper processing so that the content is not reduced. The first step is to cut roots and leaves from bawang dayak, then wash them in running water, then slice them in a slice and then dry them, before finally storing them in airtight containers. Utilization of bawang dayak which are then processed into tea, this means encouraging the use of Borneo's unique plants into an alternative source of health and the ability to handle these plants into a product means increasing economic opportunities to contribute to solving social problems.
\end{abstract}

(c) 2019 Authors. Published by Institute for Research and Community Services Universitas Muhammadiyah Palangkaraya. This is Open Access article under the CC-BY-SA License (http://creativecommons.org/licenses/by-sa/4.0/). DOI: https://doi.org/10.33084/pengabdianmu.v4i2.812.

\section{PENDAHULUAN}

Penyakit kencing manis (diabetes melitus, DM) dan tekanan darah tinggi (hipertensi masuk) dalam kategori
Penyakit Tidak Menular (PTM) yang selalu saja meningkat jumlahnya setiap tahun. Peningkatan ini terjadi baik di layanan kesehatan primer seperti Pusat Kesehatan Masyarakat (Puskesmas) maupun di rumah 
sakit (Kementerian Kesehatan Republik Indonesia, 2019; Putri \& Isfandiari, 2013). Saat ini Indonesia sedang menghadapi masalah beban ganda penyakit, yaitu disatu pihak masih terdapat banyak kasus penyakit infeksi yang harus ditangani, dilain pihak jumlah kasus PTM semakin meningkat (Rahajeng, 2011).

Berdasarkan data Riskesdas tahun 2018, DM dan hipertensi termasuk jenis PTM yang perlu mendapatkan perhatian lebih karena prevalensinya yang terus meningkat. Prevalensi DM pada penduduk berumur 15 tahun ke atas di Indonesia tahun 2018 meningkat di hampir seluruh wilayah di Indonesia kecuali di NTT, dengan rata-rata angka prevalensi di seluruh wilayah Indonesia adalah 2,0\%, meningkat dari 1,5\% pada Tahun 2013 (Badan Penelitian dan Pengembangan Kesehatan Kementerian Kesehatan Republik Indonesia, 2019).

Provinsi Kalimantan Timur termasuk daerah di Indonesia dengan prevalensi DM paling tinggi seIndonesia dengan menempati urutan kedua prevalensi paling tinggi setelah DKI Jakarta, sementara prevalensi untuk hipertensi menempati urutan ketiga se-Indonesia setelah Kalimantan Selatan dan Jawa Barat, melebihi rata-arata prevalensi nasional sebesar 34,1\% (Badan Penelitian dan Pengembangan Kesehatan Kementerian Kesehatan Republik Indonesia, 2019). Namun 75,8\% kasus hipertensi di Indonesia belum terdiagnosis dan belum terjangkau pelayanan kesehatan sehingga prevalensi sesungguhnya bisa jadi lebih tinggi dibandingkan yang terlapor (Rahajeng, 2011).

Ketidakpatuhan pengobatan dan pengelolaan yang tidak baik pada penyakit DM dan hipertensi dapat mengakibatkan terjadinya komplikasi dengan berbagai penyakit seperti stroke, gagal jantung, dan gagal ginjal dengan tingkat mortalitas yang tinggi. Kedua penyakit ini dapat menimbulkan beban ekonomi yang sangat besar bila telah terjadi komplikasi yang berat (Fatimah, 2015; Risnasari, 2014).
Mengingat baik DM dan hipertensi akan memberikan dampak terhadap kualitas pasien dan peningkatan biaya kesehatan yang besar, maka semua pihak baik masyarakat maupun pemerintah sudah seharusnya ikut serta dalam usaha penanggulangan kedua penyakit ini, khususnya dalam upaya pencegahan (Pradana et al., 2018; Rosdiana et al., 2017). Oleh karena itu perlu dilakukan upaya untuk meningkatkan kepedulian masyarakat dalam mencegah dan mengendalikan PTM termasuk DM. Pemberdayaan masyarakat dalam pengendalian PTM dalam hal ini seyogyanya dilakukan oleh kader puskesmas (Restuastuti \& Restila, 2018; Kementerian Kesehatan Republik Indonesia, 2013).

Puskesmas Harapan Baru adalah salah satu Puskesmas di Kecamatan Loa Janan Mir, Kota Samarinda, Provinsi Kalimantan Timur, Indonesia. Puskesmas Harapan Baru merupakan merupakan salah satu puskesmas yang berada di Kecamatan Samarinda Seberang dengan luas wilayah 1128,01 Ha dimana puskesmas tersebut melayani dua kelurahan yaitu Kelurahan Harapan Baru dan Kelurahan Sengkotek. Data dasar perbatasan Puskesmas Harapan baru adalah sebagai berikut:

1. Sebelah utara: perbatasan dengan Sungai Mahakam

2. Sebelah selatan: perbatasan dengan Simpang Tiga Balikpapan, Tenggarong

3. Sebelah timur: perbatasan dengan Kelurahan Sungai Keledang serta Kelurahan Rapak Dalam, dan

4. Sebelah barat: perbatasan dengan Simpang Pasir Menurut data kunjungan dari Puskesmas Harapan Baru didapatkan DM dan hipertensi menempati urutan pertama dan kedua dari 10 PTM terbanyak dan terus meningkat setiap tahunnya. Pada tahun 2015 jumlah penderita DM sebanyak 2.404 orang (12.19\%) dari 13.129 orang, tahun 2016 meningkat menjadi 2.354 orang (22.93\%) dari 10.493 orang, sedangkan tahun 2017 periode Januari-Desember sebanyak 1.431 orang dimana 
1.227 orang $(85.7 \%)$ berusia diatas 45 tahun (Dinas Kesehatan Kota Samarinda, 2018).

Bawang dayak adalah tanaman khas Kalimantan yang digunakan oleh masyarakat Suku Dayak sebagai obat. Tumbuhan ini memiliki tinggi sekitar 30-40 cm. Bentuk umbi pada bawang dayak berwarna merah berlapis, berdaun tunggal seperti pita dengan ujung dan pangkal runcing tepi rata atau tidak bergerigi berwarna hijau. Memiliki bunga majemuk yang tumbuh di ujung batang berwarna putih dengan putik berbentuk jarum berukuran kurang lebih $4 \mathrm{~mm}$ berwara putih kekuningan, dan memiliki akar serabut berwarna cokelat muda (Naspiah et al., 2014; Galingging, 2007).

Dari segi kesehatan kandungan yang terdapat dalam bawang dayak seperti alkaloid, glikosid, flavonoid, fenolik, steroid dan tanin memiliki manfaat sebagai hipoglikemik yaitu mampu menurunkan kadar gula darah serta antioksidan yang mampu menangkal radikal bebas serta mampu menurunkan kolesterol, kemudian dari segi ekonomis teh bawang dayak ini memberikan peluang untuk dijadikan produk herbal olahan yang memiliki nilai jual tinggi (Setyawan \& Masnina, 2018; Puspadewi et al., 2013).

Kegiatan pengabdian masyarakat ini memfokuskan kepada kader Puskesmas karena merupakan ujung tombak pelayanan kesehatan yang selalu bertemu dengan masyarakat yang berobat, diharapkan setelah kegiatan ini dapat membagikan ilmu yang didapatkan kepada masyarakat mengenai pengolahan teh bawang dayak dan manfaat untuk kesehatan, selain itu juga memiliki manfaat dari segi ekonomi.

Selain itu, kader puskesmas menjalankan tugasnya dalam memantau setiap perkembangan kesehatan daerah binaan, bekerja dengan ikhlas tanpa mendapatkan penghasilan tetap sehingga perlu dilakukan suatu kegiatan yang bertujuan untuk menambah pengetahuan mereka berupa manfaat ekonomi dari teh bawang dayak yang dapat dijual kepada orang terdekat ataupun masyarakat sekitar tanpa mengganggu pekerjaan utama mereka sebagai kader kesehatan.

\section{METODOLOGI}

Kegiatan pengabdian ini dilaksanakan di Puskesmas Harapan Baru Samarinda Seberang. Metode yang digunakan dalam pengabdian ini adalah berupa pendidikan kesehatan tentang DM dan hipertensi dan demonstrasi pengolahan teh bawang dayak. Peserta pada kegiatan ini adalah kader kesehatan Puskesmas Harapan Baru Samarinda Seberang yang dihadiri sebanyak 30 kader kesehatan.

Pada kegiatan ini peserta diberikan informasi dan keterampilan dalam memanfaatkan umbi bawang dayak menjadi teh yang berfungsi untuk menurunkan kadar gula darah dan menurunkan tekanan darah pada penderita hipertensi. Pendidikan kesehatan tentang DM dan hipertensi membahas mengenai penyebab penyakit, tanda dan gejala penyakit, klasifikasi penyakit, pengobatan herbal salah satunya yaitu dengan mengkonsumsi teh bawang dayak yang terbukti secara ilmiah mampu menurunkan gula darah dan tekanan darah. Kegiatan selanjutnya yaitu demonstrasi pembuatan teh bawang dayak yang merupakan tanaman asli Kalimantan memiliki khasiat menurunkan gula darah pada penderita DM dan menurunkan tekanan darah pada penderita hipertensi.

\section{HASIL DAN PEMBAHASAN}

Kegiatan yang dilakukan pada kegiatan pengabdian ini adalan pendidikan kesehatan dan demonstrasi pembuatan teh bawang dayak. Kegiatan ini dilaksanakan dengan mitra Puskesmas Harapan Baru Samarinda Seberang. Kegiatan ini dihadiri oleh 30 kader kesehatan. Kegiatan ini melibatkan dua orang 
mahasiswa Program Studi Diploma III Keperawwatan Universitas Muhammadiyah Kalimantan Timur dan juga petugas Puskesmas Harapan Baru Samarinda Seberang sebanyak tiga orang dan dilaksanakan pada hari Kamis tanggal 2 Mei 2019 diketuai oleh Ns. Annaas Budi Setyawan, M.Si., Med dan beranggotakan Ns. Arief Budiman, M.Kep serta Ns. Taufik Septiawan, M.Kep.

Kegiatan pengabdian masyarakat ini dibuka langsung oleh kepala Puskesmas Harapan Baru dr. Siti Mardiah Thahir serta di hadiri oleh puluhan kader yang antusias mengikuti serta mendemonstrasikan cara pembuatan teh bawang dayak dari awal hingga selesai acara, disamping itu didalam kegiatan ini juga diberikan pendidikan kesehatan kepada para kader mengenai hipertensi dan juga penyakit DM.

Pendidikan kesehatan tentang penyakit DM dan hipertensi diberikan agar kader mengenal dan memahami penyakit ini lebih dalam. Penyampaian mengenai penjelasan penyakit, penyebab penyakit, tanda dan gejala penyakit, serta pengobatan herbal yang diberikan salah satunya adalah teh bawang dayak dengan kandungan flavonoid dan tannin memiliki efek hipoglikemi untuk menurunkan gula darah, selain itu juga memiliki kandungan antioksidan yang mampu untuk menurunkan tekanan darah pada penderita hipertensi. Dokumentasi kegiatan penyampaian Informasi disajikan pada Gambar 1.

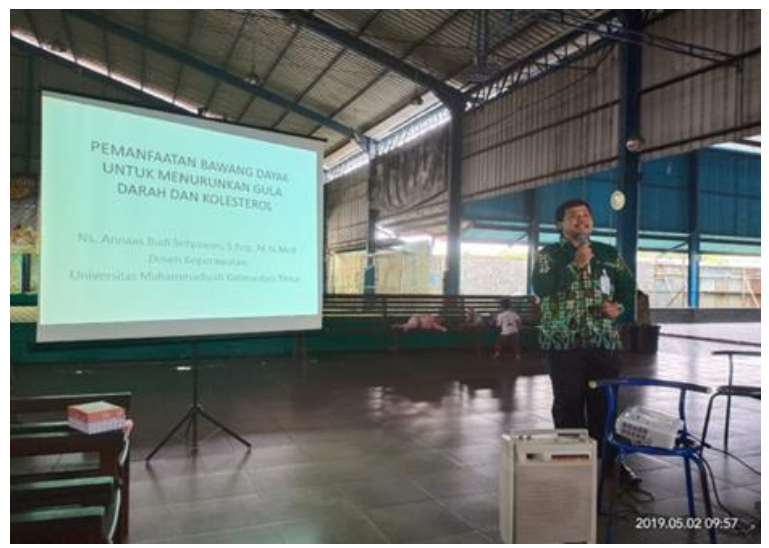

Gambar 1. Penyampaian informasi tentang DM dan hipertensi pada kader puskesmas
Demonstrasi teh bawang dayak dimulai dengan pengenalan tanaman bawang dayak yang merupakan tanaman asli Kalimantan yang memiliki banyak khasiat bagi kesehatan. Dalam memanfaatkan tanaman bawang dayak ini perlu pengolahan yang baik agar kandungannya tidak berkurang langkah pertama yaitu memotong akar dan daun dari bawang dayak selanjutnya dicuci pada air yang mengalir kemudian di iris secara menyerong dan dikeringkan selanjutnya langkah terakhir yaitu disimpan dalam wadah yang kedap udara. Demonstrasi pembuatan teh bawang dayak serta hasil seduhan teh bawang dayak secara berturut-turut disajikan pada Gambar 2 dan 3.

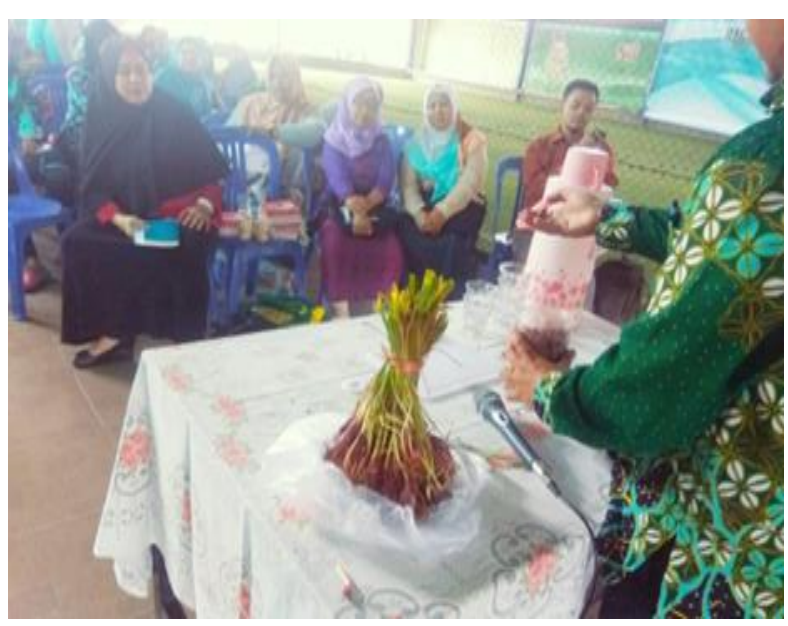

Gambar 2. Demonstrasi pembuatan teh bawang dayak

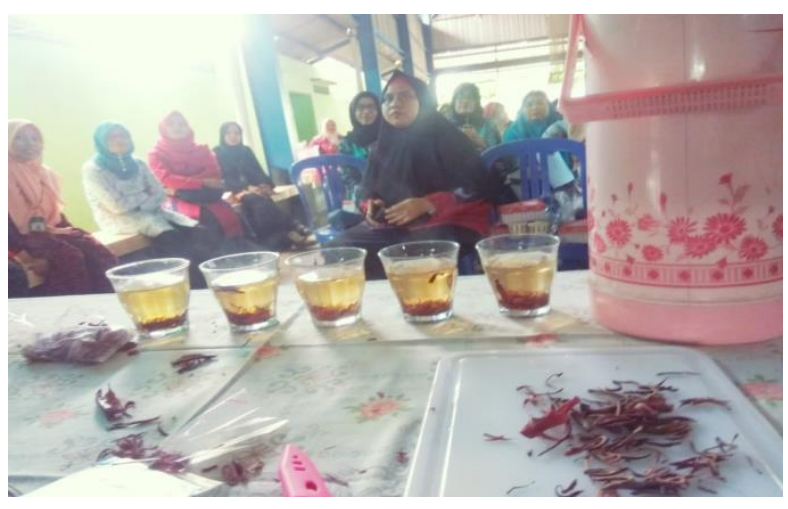

Gambar 3. Hasil seduhan teh bawang dayak yang telah dibuat 
Kegiatan ini diikuti kader dengan sangat antusias, hal itu bisa terlihat dari banyaknya pertanyaan yang diberikan kepada narasumber terkait pembuatan teh bawang dayak serta terkait penyakit diabetes mellitus dan hipertensi. Selain itu evaluasi kegiatan ini juga dilakukan dengan cara memberikan pertanyaan kepada kader dan terlihat kader dapat menjawab pertanyaan yang diberikan. Kegiatan pengabdian masyarakat ini terdokumentasi dengan baik, secara keseluruhan kegiatan dapat dilihat secara daring melalui tautan berikut:

https://www.youtube.com/watch?v=87W1UgEfPqg\& $\mathrm{t}=21 \mathrm{~s}$

\section{KESIMPULAN}

Pelaksanaan Pengabdian masyarakat ini juga sejalan dengan Visi dan Misi Universitas Muhammadiyah Kalimantan Timur, dengan adanya pemanfaatan bawang dayak yang kemudian di olah menjadi teh hal ini berarti mendorong pemanfaatan tanaman khas Kalimantan menjadi sumber alternatif bagi kesehatan serta kemampuan untuk mengolah tanaman ini menjadi sebuah produk berarti meningkatkan peluang ekonomi untuk berkontibusi dalam penyelesaian masalah sosial.

\section{UCAPAN TERIMA KASIH}

Penulis mengucapkan terima kasih kepada Pimpinan Puskesmas Harapan Baru Samarinda Seberang dr. Siti Mardiah Thahir atas apresiasi dan kerja sama yang terjalin. Kepada LPPM Universitas Muhammadiyah Kalimantan Timur atas hibah internal pengabdian masyarakat pelaksanaan Tahun 2019.

\section{REFERENSI}

Badan Penelitian dan Pengembangan Kesehatan Kementerian Kesehatan Republik Indonesia. 2019. Hasil Utama Riset Kesehatan Dasar Tahun
2018. Jakarta: Badan Penelitian dan Pengembangan Kesehatan Kementerian Kesehatan Republik Indonesia.

Dinas Kesehatan Kota Samarinda. 2018. Profil Kesehatan Kota Samarinda Tahun 2018. Samarinda: Dinas Kesehatan Kota Samarinda.

Fatimah, R.N. 2015. Diabetes Melitus Tipe 2. Majority (Medical Journal of Lampung University). 4(5):93101.

Galingging, R.Y. 2007. Potensi Plasma Nutfah Tanaman Obat sebagai Sumber Biofarmaka di Kalimantan Tengah. Jurnal Pengkajian dan Pengembangan Teknologi Pertanian. 10(1):76-83. http:/ /dx.doi.org/10.21082/jpptp.v10n1.2007 .p\%25p

Kementerian Kesehatan Republik Indonesia. 2019. Data dan Informasi Profil Kesehatan Indonesia 2018. Jakarta: Pusat Data dan Informasi Kementerian Kesehatan Republik Indonesia.

Kementerian Kesehatan Republik Indonesia. 2013. Pedoman Teknis Penemuan dan Tatalaksana Hipertensi. Jakarta: Direktorat Pengendalian Penyakit Tidak Menular Kementerian Kesehatan Republik Indonesia.

Naspiah, N., Iskandar, Y., Moektiwardoyo, M. 2014. Artikel Ulasan: Bawang Tiwai (Eleutherine americana Merr.), Tanaman Multiguna. Indonesian Journal of Applied Sciences. 4(2):18-30. https://doi.org/10.24198/.v4i2.16820

Pradana, D.A., Marfianti, E., Trimulyaningsih, N. 2018. Iptek Bagi Masyarakat (IbM) Desa Terong dan Jatimulyo dalam Pengelolaan Hipertensi dan Diabetes Melitus. AJIE (Asian Journal of Innovation and Entrepreneurship). 3(2):96-106.

Puspadewi, R., Adirestuti, P., Menawati, R. 2013. Khasiat Umbi Bawang Dayak (Eleutherine palmifolia (1.) Merr.) sebagai Herbal Antimikroba Kulit. Kartika: Jurnal Imiah Farmasi. 1(1):31-37. http:/ /dx.doi.org/10.26874/kjif.v1i1.21

Putri, N.H.K., Isfandiari, M.A. 2013. Hubungan Empat Pilar Pengendalian DM Tipe 2 dengan Rerata Kadar Gula Darah. Jurnal Berkala Epidemiologi. 1(2):234-243.

Rahajeng, E. 2011. Upaya Pengendalian Penyakit Tidak Menular di Indonesia. Buletin Jendela Data dan Informasi Kesehatan. 2(2):23-28. 
Restuastuti, T., Restila, R. 2018. Analisis Pemberdayaan Masyarakat sebagai Upaya Pencegahan Penyakit Tidak Menular melalui Posbindu PTM di Kecamatan XIII Koto Kampar Kabupaten Kampar Riau. Asian Journal of Environment, History and Heritage. 2(1):51-58.

Risnasari, N. 2014. Hubungan Tingkat Kepatuhan Diet Pasien Diabetes Mellitus dengan Munculnya Komplikasi di Puskesmas Pesantren Ilkota Kediri. Efektor. 1(25):15-19.

Rosdiana, A.I., Raharjo, B.B., Indarjo, S. 2017. Implementasi Program Pengelolaan Penyakit Kronis (Prolanis). Higeia: Journal of Public Health Research and Development. 1(3):140-150.

Setyawan, A.B., Masnina, R. 2018. Efektivitas Teh Bawang Dayak untuk Menurunkan Kadar Gula Darah Pasien Diabetes Mellitus Tipe 2. STRADA: Jurnal Ilmiah Kesehatan. 7(2):7-13. 